\title{
Effect of a Traditional Processing Method on the Chemical Composition of Local White Lupin (Lupinus albus L.) Seed in North-Western Ethiopia
}

\author{
Likawent Yeheyis $^{\mathrm{a}, \mathrm{b}, *}$, Claudia Kijora ${ }^{\mathrm{b}}$, Michael Wink ${ }^{\mathrm{c}}$, and Kurt J. Peters ${ }^{\mathrm{b}}$
}

a Amhara Region Agricultural Research Institute, Debre Birhan Centre, P. O. Box 112, Debre Birhan, Ethiopia. E-mail: likawenty@yahoo.com

b Institute of Animal Science, Humboldt University of Berlin, Philippstr. 13, Haus 9, D-10115 Berlin, Germany

c Institute of Pharmacy and Molecular Biotechnology, Heidelberg University, Im Neuenheimer Feld 364, D-69120 Heidelberg, Germany

* Author for correspondence and reprint requests

Z. Naturforsch. 66 c, 403 -408 (2011); received October 13, 2010/March 30, 2011

The effect of a traditional Ethiopian lupin processing method on the chemical composition of lupin seed samples was studied. Two sampling districts, namely Mecha and Sekela, representing the mid- and high-altitude areas of north-western Ethiopia, respectively, were randomly selected. Different types of traditionally processed and marketed lupin seed samples (raw, roasted, and finished) were collected in six replications from each district. Raw samples are unprocessed, and roasted samples are roasted using firewood. Finished samples are those ready for human consumption as snack. Thousand seed weight for raw and roasted samples within a study district was similar $(P>0.05)$, but it was lower $(P<0.01)$ for finished samples compared to raw and roasted samples. The crude fibre content of finished lupin seed sample from Mecha was lower $(P<0.01)$ than that of raw and roasted samples. However, the different lupin samples from Sekela had similar crude fibre content $(P>0.05)$. The crude protein and crude fat contents of finished samples within a study district were higher $(P<0.01)$ than those of raw and roasted samples, respectively. Roasting had no effect on the crude protein content of lupin seed samples. The crude ash content of raw and roasted lupin samples within a study district was higher $(P<0.01)$ than that of finished lupin samples of the respective study districts. The content of quinolizidine alkaloids of finished lupin samples was lower than that of raw and roasted samples. There was also an interaction effect between location and lupin sample type. The traditional processing method of lupin seeds in Ethiopia has a positive contribution improving the crude protein and crude fat content, and lowering the alkaloid content of the finished product. The study showed the possibility of adopting the traditional processing method to process bitter white lupin for the use as protein supplement in livestock feed in Ethiopia, but further work has to be done on the processing method and animal evaluation.

Key words: White Lupin, Traditional Processing, Lupin Alkaloids

\section{Introduction}

Lupin cultivation in the world is targeted for the use of the crop as livestock feed, soil fertilizer, and human food. One of the limitations of lupin is its alkaloid content which is responsible for bitter taste and toxicity of lupin products in human food and livestock feed. Based on their content of tox-

Abbreviations: SE, standard error; Ra, raw; Ro, roasted; Fi, finished; DM, dry matter; $\mathrm{CF}$, crude fibre; $\mathrm{CP}$, crude protein; EE, crude fat; CA, crude ash; MeRa, Mecha raw; MeRo, Mecha roasted; MeFi, Mecha finished; SeRa, Sekela raw; SeRo, Sekela roasted; SeFi, Sekela finished. ic quinolizidine alkaloids the available cultivated lupins in the world (Lupinus albus, L. angustifolius, L. mutabilis, L. luteus) are categorized into two groups; bitter and sweet varieties. According to Wink (2008), bitter lupin varieties have alkaloid contents ranging between $0.5-6 \%$ and sweet varieties have less than $0.02 \%$. However, their relatively high protein content $(30-48 \%)$ makes them an important protein source in livestock feed and human food (Moss et al., 1996; Gdala et al., 1999; Feldheim, 1999; Jansen, 2006; Sujak et al., 2006).

The common form of lupin food products for human consumption in the developing world is 
as a snack. In the developed world it is also used for the production of noodles, bread, cookies, and cakes with attractive colour, taste, and aroma (Feldheim, 1999; Erbas et al., 2005). Feldheim (1999) reported that, with regard to appearance, acceptability, and cooking performance, noodles containing $10 \%$ lupin flour are better than a reference product without lupin flour. In addition, lupin seed is a very important livestock feed; several studies showed that lupin seed has a potential to substitute soybean meal in ruminant diet (May et al., 1993; Urbaniak, 1996; Mukisira, 1999; Froidmont et al., 2004). It is also an important crop for organic livestock farms by playing the role of soybean meal.

When lupins are soaked in water, the watersoluble alkaloids can be leached out. This is an old finding and was already practiced in ancient Greece and by Indians in the Andes. In northwestern Ethiopia white lupin seed, a bitter local variety, is traditionally used for human food as a snack. Though feed shortage is a big problem, lupin is hardly used as livestock feed in the area due to its high alkaloid content. In this area, traditionally lupin snack is said to be the poor man's meat. However, the preparation of lupin snack from lupin seed requires several difficult processing steps to get rid of the bitter taste and improve its chewing characteristics for human consumption. The major steps according to their order are roasting, soaking in water (4-9 days), and washing twice (Yeheyis et al., 2010). Among the processing steps, according to farmers' belief, roasting is the key step to get rid of the bitter taste and attain the required level of chewing characteristics of the snack. However, the effect of the traditional processing method on the chemical composition of lupin seed in the areas where it is being grown and used as a snack is not known. In addition, knowledge on the effect of this processing method could provide basic information to process the local lupin seed for the use in livestock feed. Thus, this survey and laboratory evaluation study was conducted with the objective of evaluating the effect of the traditional lupin processing method on different types of lupin seed samples, collected from two major agro-ecological zones (mid- and high-altitude areas) of north-western Ethiopia, so as to indicate if there are possibilities to develop traditional lupin processing steps for the use of the crop as livestock feed.

\section{Material and Methods}

\section{Sample collection sites}

North-western Ethiopia is the area in which lupin is widely grown. The samples were collected from Mecha and Sekela administrative districts in west Gojjam administrative zone, north-western Ethiopia, in July 2009. The altitudinal range is between 1807 and $2300 \mathrm{~m}$ above sea level in Mecha district, and 2013 and $3257 \mathrm{~m}$ above sea level in Sekela district. The average annual rainfall in Mecha district is $1537 \mathrm{~mm}$ with a monomodal distribution from May to September, and in Sekela it is $1738 \mathrm{~mm}$ with a bimodal distribution from February to April and from June to September. The average annual minimum and maximum temperatures are is 10 and $27^{\circ} \mathrm{C}$ in Mecha district, and 8 and $21^{\circ} \mathrm{C}$ in Sekela district (Worldclim, 2009). Mecha has relatively fertile soil. The topography in Mecha is characterized by plain landscape with scattered trees on farmlands, whereas the topography in Sekela is undulating landscape with degraded farmlands. Mixed croplivestock production with low input-output is the typical farming system in the two districts.

\section{Sample type and sample collection}

The lupin seeds used in this study were from the local white lupin (Lupinus albus L.), bitter variety, which is widely cultivated in north-western Ethiopia by smallholders.

Multi-stage and purposive sampling methods were used to select study districts for lupin seeds sampling. First, west Gojjam zone was randomly selected from north-western Ethiopia. Second, the zone was classified into two clusters to represent the mid- and high-altitude lupin growing areas. Then, Mecha and Sekela districts were selected purposively based on the status of lupin production to represent the mid- and highaltitude areas, respectively. Lupin seed samples were collected from local markets of the respective study districts. To evaluate the effect of the different processing steps of lupin on chemical composition three types of lupin seed samples [raw (Ra), roasted (Ro), and finished (Fi)] were collected from each district. The different types of lupin samples for each district were collected in six replications from six different farmers who sold their products on the market. Farmer selection at the market during sample collection was 
Table I. Mean thousand seed weight, proximate composition, and alkaloid content of the different types of lupin seed samples from Mecha and Sekela districts of north-western Ethiopia.

\begin{tabular}{lcccc|cccc}
\hline & \multicolumn{4}{c|}{ Mecha } & \multicolumn{4}{c}{ Sekela } \\
\cline { 2 - 9 } & Ra & Ro & Fi & SE & Ra & Ro & Fi & SE \\
\hline Thousand seed weight $(\mathrm{g})$ & $287^{\mathrm{a}}$ & $305^{\mathrm{a}}$ & $210^{\mathrm{b}}$ & 9.40 & $296^{\mathrm{a}}$ & $298^{\mathrm{a}}$ & $231^{\mathrm{b}}$ & 9.53 \\
DM (g/kg) & $913.8^{\mathrm{a}}$ & $926.7^{\mathrm{b}}$ & $911.5^{\mathrm{a}}$ & 1.41 & $910.5^{\mathrm{a}}$ & $922.9^{\mathrm{b}}$ & $903.6^{\mathrm{a}}$ & 1.72 \\
CF (g/kg DM) & $135.3^{\mathrm{a}}$ & $126.9^{\mathrm{a}}$ & $73.9^{\mathrm{b}}$ & 3.47 & $132.8^{\mathrm{a}}$ & $128.4^{\mathrm{a}}$ & $126.7^{\mathrm{a}}$ & 2.19 \\
CP (g/kg DM) & $367.6^{\mathrm{a}}$ & $387.7^{\mathrm{a}}$ & $528.3^{\mathrm{b}}$ & 7.78 & $409.9^{\mathrm{a}}$ & $394.1^{\mathrm{a}}$ & $491.1^{\mathrm{b}}$ & 7.13 \\
EE (g/kg DM) & $81.7^{\mathrm{a}}$ & $87.6^{\mathrm{a}}$ & $124.5^{\mathrm{b}}$ & 1.23 & $78.1^{\mathrm{a}}$ & $83.1^{\mathrm{a}}$ & $109.8^{\mathrm{b}}$ & 2.70 \\
CA (g/kg DM) & $32.1^{\mathrm{a}}$ & $30.8^{\mathrm{a}}$ & $20.1^{\mathrm{b}}$ & 0.56 & $28.7^{\mathrm{a}}$ & $30.2^{\mathrm{a}}$ & $18.5^{\mathrm{b}}$ & 0.49 \\
Alkaloid (\%)* & 1.17 & 1.29 & 0.10 & - & 1.43 & 1.07 & 0.03 & - \\
\hline
\end{tabular}

Means within study district in a row followed by different superscripts differ significantly $(P<0.01)$.

* Statistical analysis was not done.

SE, standard error; Ra, raw; Ro, roasted; Fi, finished; DM, dry matter; CF, crude fibre; CP, crude protein; EE, crude fat; CA, crude ash.

random for all types of lupin seed samples. Ra samples are lupin seeds without any processing treatments. Ra samples were already well dried at the time of sampling for safe storage. Ro lupin samples are lupin seeds roasted over fire. To get six replications of Ro lupin seed samples, raw lupin seeds were collected from different farmers at the market and roasted according to the traditional farmers' practice. Roasting was done on a hot plate with firewood. Lupin seeds were roasted until a black mark was seen at the centre of the seeds. Fi lupin samples are processed and ready for human consumption as a snack. The Fi lupin samples are sold and consumed wet. Thus, the samples were air-dried immediately after sampling to get rid of the moisture for safe storage. To avoid any foreign material and to ensure the purity of the samples, impurities of all lupin seed samples were cleaned by hand.

\section{Chemical analysis}

The collected samples were ground using a hammer mill to pass through a 1-mm stainless steel sieve. The ground samples were analysed for dry matter (DM), crude fibre (CF), crude protein (CP), crude fat (EE), and crude ash (CA) content according to the procedures described by AOAC (1990). The alkaloid content of the samples was determined by capillary gas-liquid-chromatography (GLC) and GLC-mass spectrometry (MS) according to the procedures described by Wink et al. (1995). First the ground samples were homogenized in $0.5 \mathrm{M} \mathrm{HCl}$ solution. This homogenate was adjusted to $\mathrm{pH} 12$ with $6 \mathrm{~m}$ aqueous $\mathrm{NaOH}$. Then from this solution the alkaloids were extracted by a solid phase extraction method and analysed by GLC-MS. The values of all chemical composition parameters are expressed on DM basis.

\section{Data analysis}

The collected data was analysed using the general linear model (GLM) of SAS (2008). The general model used for analysis was $Y i j=\mu+l i+s j$ $+(l s) i j+e i j$, where $Y i j$ is the response variable, $\mu$ the overall mean, $l i$ the location effect, $s j$ the sample type effect, $(l s) i j$ the location by sample type interaction effect, and eij the random error. Mean separation was done using Turkey's honestly significant difference test.

\section{Results}

Seed weight and chemical composition of the different lupin seed samples from the two studied districts are presented in Table I. Thousand seed weights for $\mathrm{Ra}$ and Ro samples within the studied district were similar $(P>0.05)$. However, it was lower for Fi samples $(P<0.01)$. The DM content for $\mathrm{Ra}$ and Fi samples within the studied district was also similar $(P>0.05)$, whereas the DM content of Ro lupin seed samples in both studied districts was higher $(P<0.01)$ than that of the respective $\mathrm{Ra}$ and Fi samples. There was no interaction effect $(P>0.05)$ observed between studied district and type of lupin sample for both thousand seed weight and DM content (Table II).

The CP content of Fi samples within the studied district was higher $(P<0.01)$ than that of $\mathrm{Ra}$ and Ro samples. However, roasting had no effect on the CP content of lupin samples. A significant 
Table II. The interaction effect between study district and lupin sample type for thousand seed weight and proximate composition of the different lupin samples from Mecha and Sekela districts of north-western Ethiopia.

\begin{tabular}{lcccc}
\hline Parameter & \multicolumn{3}{c}{$\begin{array}{c}\text { Location by lupin sample } \\
\text { type interaction }\end{array}$} & SE \\
\cline { 2 - 4 } & $\begin{array}{c}\text { MeRa x } \\
\text { SeRa }\end{array}$ & $\begin{array}{c}\text { MeRo x } \\
\text { SeRo }\end{array}$ & $\begin{array}{c}\text { MeFi x } \\
\text { SeFi }\end{array}$ & \\
\hline Thousand seed & ns & ns & ns & 9.46 \\
weight $(g)$ & & & & \\
DM (g/kg) & ns & ns & ns & 1.57 \\
CF (g/kg DM) & ns & ns & $* *$ & 2.90 \\
CP (g/kg DM) & $* *$ & ns & ns & 7.47 \\
EE (g/kg DM) & ns & ns & $*$ & 2.09 \\
CA (g/kg DM) & $*$ & ns & ns & 0.53 \\
\hline
\end{tabular}

$* P<0.05 ; * * P<0.01 ;$ ns, not significant.

$\mathrm{SE}$, standard error; DM, dry matter; $\mathrm{CF}$, crude fibre; $\mathrm{CP}$, crude protein; EE, crude fat; CA, crude ash; MeRa, Mecha raw; MeRo, Mecha roasted; MeFi, Mecha finished; SeRa, Sekela raw; SeRo, Sekela roasted; SeFi, Sekela finished.

interaction effect $(P<0.01)$ was observed for the $\mathrm{CP}$ content between study district and $\mathrm{Ra}$ lupin samples. The $\mathrm{CP}$ content of Ra lupin seeds from Sekela $(409.9 \mathrm{~g} / \mathrm{kg} \mathrm{DM})$ was higher $(P<$ $0.01)$ than that of samples from Mecha $(367.6 \mathrm{~g} /$ $\mathrm{kg}$ DM). The CF content of Fi lupin seeds from Mecha was lower than that of Ra and Ro samples $(P<0.01)$. However, samples from Sekela had similar CF contents $(P>0.05)$. An interaction effect was observed $(P<0.01)$ for the CF content between study districts and Fi samples. The CF content of Fi sample from Sekela $(126.7 \mathrm{~g} /$ $\mathrm{kg} \mathrm{DM})$ was higher $(P<0.01)$ than that of the Fi sample from Mecha $(73.9 \mathrm{~g} / \mathrm{kg}$ DM). The EE content of Fi lupin samples within the studied district was higher $(P<0.01)$ than that of the Ra and Ro lupin samples of the respective study districts. However, the EE content of Fi lupin samples from Mecha was higher $(P<0.05)$ than that of the same type of lupin samples from Sekela. Processing lupin seeds had also a considerable negative effect on the CA content of the finished lupin product. The CA content of $\mathrm{Ra}$ and Ro lupin samples within the studied district was higher $(P<0.01)$ than that of the Fi lupin samples of the respective study districts. There was also a significant interaction effect $(P<0.05)$ for the CA content between study district and Ra lupin samples.

Even though statistical analysis was not done, the alkaloid content of $\mathrm{Fi}$ samples from both study districts was lower than that of $\mathrm{Ra}$ and Ro samples (Table I). On the other hand, the alkaloid content of Ra and Ro samples within and between study districts was closely similar, ranging between 1.07 and $1.43 \%$. The major quinolizidine alkaloids detected in all types of lupin samples were lupanine, 13-hydroxylupanine, albine, multiflorine, angustifoline, tetrahydrorhombifoline, and ester alkaloids.

\section{Discussion}

In his study of hydration kinetics on Ethiopian white lupin Solomon (2007) reported a CP, EE, $\mathrm{CF}$, and CA content of $34 \%, 14 \%, 8 \%$, and $3 \%$, respectively. The variation in $\mathrm{EE}$ and $\mathrm{CF}$ content in comparison with the present study could be due to variations in sampling sites. Thousand seed weights of $\mathrm{Ra}$ samples reported in the present study are similar to those reported by Gdala et al. (1999) (295 g) for white lupins in Poland, whereas they are at variance with those reported by Erbas et al. (2005) (411 g) for white lupins in Turkey probably due to variety and location differences. The lower thousand seed weight of Fi samples in both study districts as compared to $\mathrm{Ra}$ and Ro samples is expected and could be associated with the effect of the washing process which could remove part of the hull of the seeds. The hull of lupin seeds makes up $20-25 \%$ of the total seed weight (Gdala et al., 1999; Brillouet and Carre, 1989), and hence removal of part of this seed component could affect the seed weight significantly. Ro samples from both study districts had a higher DM content which could be attributed to the drying effect of the roasting processing step. Processing had lowered the CF content of Fi samples from Mecha compared to Ra and Ro samples, but a similar CF content was obtained from all types of lupin samples from Sekela. This variation in $\mathrm{CF}$ content of Fi samples between study districts could be associated with the difference in the degree of the intensity of the processing steps (especially during washing) applied on lupin seeds in the two study districts. Similarly, processing affected the CA content of Fi samples negatively in both study districts which could be due to CA losses associated with removal of part of the hull during processing. According to Smulikowska et al. (1995) the hull of white lupin contains a relatively large amount $(2.7 \%)$ of CA. Generally, processing lupin seeds lowered the thousand seed weight, CF and CA values of Fi lupin samples from Mecha 
by $27 \%, 45 \%$, and $37 \%$, and from Sekela by $22 \%$, $5 \%$, and $19 \%$, respectively.

Processing lupin seeds had a positive effect on $\mathrm{CP}$ and $\mathrm{EE}$ contents of Fi lupin samples from both study districts. It improved the $\mathrm{CP}$ and $\mathrm{EE}$ content of Fi lupin samples from Mecha by $44 \%$ and $52 \%$, and from Sekela by $20 \%$ and $41 \%$, respectively. From the proximate composition point of view, this result depicts the potential of the Fi lupin products for their use in livestock feed as protein supplement and the possibility to adopt the traditional processing method in bitter lupin seed processing for livestock feed in the area. The interaction effects observed for CP and CA contents between study districts and the Ra samples could be attributable to factors related to differences in the growing environment of the lupin crop.

The major antinutritional factors limiting the use of lupins for food and feeding purposes are quinolizidine alkaloids (QA) (such as lupanine, sparteine, and 13-hydroxylupanine) which are common both in sweet and bitter varieties of the genus Lupinus (Wink et al., 1995; Gdala et al., 1999; Zulak et al., 2006). According to Erbas et al. (2005), since most alkaloids of lupin are water-soluble, the alkaloid level of lupin $(0.5-4 \%)$ can be decreased to $0.04 \%$ by soaking in running water, in brine or by scalding. The result of the present study supports this idea. In this study the alkaloid contents of Fi lupin samples from Mecha $(0.10 \%)$ and Sekela $(0.03 \%)$ illustrate that processing lupin by soaking in running water can effectively lower the alkaloid content of bitter white lupin. The alkaloid content of Fi samples from Mecha was relatively higher than the acceptable maximum QA content $(200 \mathrm{mg} / \mathrm{kg}$ product) in lupin flour and foods set by some European countries, Australia, and New Zealand (Resta et al., 2008). However, the old age history of lupin snack consumption for humans in the two study districts and the absence of reports on health problems due to lupin snack consumption (Yeheyis et al., 2010) indicate that the relatively higher alkaloid content of Fi lupin from Mecha is safe for lupin consumption as a snack. Gross (1988) has also reported that in humans the presence of alkaloids is non-toxic at low contents $(11-46 \mathrm{mg} / \mathrm{kg}$ body weight).

Lupin alkaloids, as secondary plant metabolites, are an important parameter to consider for the use of lupin as livestock feed because of their effect on feed intake, productive performance, and animal health. According to Urbaniak (1996), sheep exhibit a higher tolerance to lupin alkaloids than monogastric animals. In a feeding trial conducted to evaluate the potential of lupin seed as a substitute for soybean meal, this author concluded that growing lambs can tolerate an alkaloid content up to $0.037 \%$ in lupin seeds. The author also suggested that growing lambs might tolerate an alkaloid content of more than $0.037 \%$, but this needs further investigation. The present study indicates that there is a possibility to lower the alkaloid content of the bitter lupin variety in Ethiopia to a safe level for livestock feeding using the traditional technique. Thus, concerning the introduction of sweet lupin varieties, there is an option that Fi lupin products can be used as livestock feed supplements in areas where lupin cultivation and utilization is popular. However, according to Yeheyis et al. (2010), the traditional lupin processing technique for human consumption in Ethiopia is difficult due to labour intensity and time consumption. In addition, it requires relatively large amounts of water. Thus, if this processing technique is to be adopted for the use of the local lupin in livestock feed, efforts must be made to simplify the processing technique for the smallholders in the study area.

\section{Conclusions}

The traditional processing method of lupin seeds in Ethiopia has a positive effect on the chemical composition of the finished lupin product by improving the crude protein and crude fat content, and by lowering the alkaloid content. However, it has a negative effect on thousand seed weight and crude ash content of the finished product. Location has an effect on the chemical composition of raw and finished lupin seed samples. The results of this study indicate that there is a possibility to adopt the traditional processing method for the use of the processed lupin as protein supplement in livestock feed. However, there has to be further investigation on the processing method itself and the effect of the processed lupin seeds on animal performance.

\section{Acknowledgement}

The first author would like to acknowledge the Deutscher Akademischer Austausch-Dienst (DAAD) for a PhD scholarship award. We are grateful to Mr. Tamiru Kibret, technical assistant 
at Debre Birhan Agricultural Research Centre, Ethiopia, for his help during sampling and sample processing. We would like to thank also the Amhara Region Agricultural Research Institute (ARARI), Ethiopia, and the Eastern and Southern Africa Partnership Program (ESAPP) for their financial support of the field work. We would like to thank also Humboldt University of Berlin, Department of Animal Production in the

AOAC (1990), Official Methods of Chemical Analysis, $15^{\text {th }}$ ed. Association of Official Analytical Chemists, Arlington, USA.

Brillouet J.-M. and Carre B. (1989), Characterization of polysaccharides from white lupin. J. Sci. Food Agric. 34, 861-865.

Erbas M., Certel M., and Uslu M. K. (2005), Some chemical properties of white lupin seeds (Lupinus albus L.). Food Chem., 89, 341-345.

Feldheim W. (1999), The use of lupins in human nutrition. In: Lupin, an Ancient Crop for the New Millenium. Proceedings of the 9th International Lupin Conference, Klink/Muritz, June 20-24, 1999 (van Santen E., Wink M., Weissmann S., and Roemer P., eds.). International Lupin Association, Canterbury, New Zealand, pp. 434-437.

Froidmont E., Wavreille J., Beckers Y., and BartiauxThill N. (2004), Utilization of lupin (Lupinus albus var. Ares) seeds in animal diets: synthetic report. In: Legumes for the Benefits of Agriculture, Nutrition and the Environment: their Genomics, their Products and their Improvement. 5th European Conference on Grain Legumes, Dijon, France, June 7-11, 2004, pp. 41-42.

Gdala J., Smulikowska S., Zdunczyk Z., and Pastuszewska B. (1999), Nutrients and anti-nutrients in three lupin species grown in Poland. In: Lupin, an Ancient Crop for the New Millenium. Proceedings of the 9th International Lupin Conference, Klink/ Muritz, June 20-24, 1999 (van Santen E., Wink M., Weissmann S., and Roemer P., eds.). International Lupin Association, Canterbury, New Zealand, pp. $425-431$.

Gross R. (1988), Lupins in human nutrition. In: Proceedings of the 5th International Lupin Conference, Poznan, Poland, July 5-8, 1988 (Twardowski T., ed.), pp. $51-63$.

Jansen P. C. M. (2006), In: Lupinus albus L. Record from Protabase (Brink M. and Belay G., eds.). PROTA (Plant Resources of Tropical Africa/Ressources végétales de l'Afrique tropicale), Wageningen, The Netherlands. http:database.prota.org/search.htm (accessed in March 2009).

May M. G., Otterby D. E., Linin J. G., Hansen W. P., Johanson D. G., and Putnam D. H. (1993), Lupins (L. albus) as a protein supplement for lactating Holstein dairy cows. J. Dairy Sci., 76, 2682-2691.

Moss B. R., Lin J. C., Reeves D. W., Kochapakdee S., Mask P. L., and van Santen E. (1996), Lupin in ruminant diets. In: Proceedings of the 8th International
Tropics and Subtropics, Germany, for the analysis of the proximate composition of the samples. Our special thanks go to the Vater und Sohn Eiselen Foundation for the financial support and A. Backhaus and F. Sporer, Institute of Pharmacy and Molecular Biotechnology, Heidelberg University, Germany, for the technical support of the alkaloid analysis.

Lupin Conference, Asilomar, CA, USA, May 11-16, 1996.

Mukisira E. A. (1999), The effect of lupin/maize meal supplementation on the performance of lactating Friesian cows. Farmers, their animals and the environment. ILRI on disc, a joint FAO/ILRI production.

Resta D., Boschin G., D'Agostina A., and Arnoldi A. (2008), Evaluation of total quinolizidine alkaloids content in lupin flours, lupin based ingredients, and foods. Mol. Nutr. Food Res., 52, 490-495.

SAS (2008), Statistical Analysis System, Version 8.2. SAS Institute Inc., Cary, NC, USA.

Smulikowska S., Wasilewko J., and Mieczkowska A. (1995), A note on the chemical composition of the cotyledons and seed coat of three species of sweet lupin. J. Anim. Feed Sci. 4, 69-76.

Solomon W. K. (2007), Hydration kinetics of lupin ( $L u$ pinus albus) seeds. J. Food Process Eng. 30, 119-130.

Sujak A., Kotlarz A., and Strobel W. (2006), Compositional and nutritional evaluation of several lupin seeds. Food Chem. 98, 711-719.

Urbaniak M. (1996), Utilization of blue lupin seed of different alkaloid levels as a substitute for soya bean meal in diets for fattening lambs. 1. Live weight gain, feed utilization and wool production. In: Proceedings of the 8th International Lupin Conference, Asilomar, CA, USA, May 11-16, 1996.

Wink M. (2008), Ecological roles of alkaloids. In: Modern Alkaloids; Structure, Isolation, Synthesis and Biology (Fattorusso E. and Taglialatela-Scafati O., eds.). Wiley-VCH, Weinheim, pp. 3-24.

Wink M., Meißner C., and Witte L. (1995), Patterns of quinolizidine alkaloids in 56 species of the genus $\mathrm{Lu}$ pinus. Phytochemistry 38, 139-153.

Worldclim (2009), Very high resolution interpolated climate surfaces for global land areas. http://www. worldclim.org/node/1 (accessed in June 2009).

Yeheyis L., Kijora C., Melaku S., Girma A., and Peters K. J. (2010), White lupin (Lupinus albus L.), the neglected multipurpose crop: Its production and utilization in the mixed crop-livestock farming system of Ethiopia. In: Livestock Research for Rural Development, Volume 22, Article \#74. Retrieved April 26, 2010, from http://www.lrrd.org/lrrd22/4/yehe22074.htm.

Zulak K. G., Liscombe D. K., Ashihara H., and Facchini P. J. (2006), Alkaloids. In: Plant Secondary Metabolites: Occurrence, Structure and Role in the Human Diet (Crozier A., Clifford M. N., and Ashihara H., eds.). Blackwell Publishing Limited, Oxford. 